\title{
RENEWABLES AND THE ROMANIAN ENERGY SYSTEM
}

\author{
Article DOI: https://doi.org/10.35219/mtd.2018.2.01 \\ Florin ONEA*, Victoria CARANFIL, Liliana RUSU \\ Department of Mechanical Engineering, University “Dunarea de Jos” of Galati, Romania \\ E-mail: florin.onea@ugal.ro
}

\begin{abstract}
The main objective of the present work is to provide a more comprehensive picture of the Romanian energy system, a special attention being given to the emerging renewable sources. As a first step, different indexes will be considered to highlight the structure of the electricity portfolios, from which the authors mention electricity access and consumption and the dioxide emissions. The obtained results will be discussed at both regional and European levels, by taking also into account the share of electricity coming from renewable sources. If one discusses about renewables, it is important to mention that most of the Romanian projects are located onshore, but since there is access to the Black Sea, the benefits coming from a marine project need also to be discussed. Finally, the authors conclude that the Romanian energy market is defined by various opportunities and challenges and, using the renewable sources, it will be possible to build a sustainable energy industry.
\end{abstract}

Keywords: Romania, renewable energy, fossil fuels, onshore, offshore, coastal environment

\section{INTRODUCTION}

In order to provide a sustainable future, it is important to have sufficient access to energy sources. A higher demand of energy will also involve the carbon dioxide $\left(\mathrm{CO}_{2}\right)$ and other greenhouse gases, which are behind the climate changes. From the energy market, the electricity sector stands out, being considered an important social and economic indicator. On a global scale, it was estimated that the percentage of people without any access to electricity has dropped from $27 \%$ (in 1990), to $15 \%$ (in 2014) [1]. The European Union (EU) is an active player on the energy market, setting some ambitious targets in the near future, such as: a) cut-green house emissions by at least $40 \%$ (until 2030) and 20\% (until 2020); b) increase the share of renewable sources by $27 \%$ (until 2030); c) improve the energy efficiency by at least $27 \%$ (until 2030). It is important to achieve these objectives because, at this moment, the EU energy sector is heavily depending on imports, which mainly comes from Russia or Norway, respectively [2].

Romania has a total population of $21,529,967$, which is distributed over an area of $238,391 \mathrm{~km}^{2}$, of which $96 \%$ is land. It is bordered by Bulgaria, Hungary, Moldova, Serbia and Ukraine being also defined by a coastline facing the Black Sea, which covers a total length of $225 \mathrm{~km} \mathrm{[3].} \mathrm{Reported} \mathrm{to} \mathrm{the}$ year 2009, the Romanian electricity generation was divided between: nuclear (17\%), hydro (25-30\%) and thermal generation, which includes coal, gas and black oil. During this time, some additional sources of energy were added to the system, from which the authors may mention those coming from wind and solar industry. At the end of 2016, it was estimated that the wind projects covered almost $6 \%$ (652 MW) from the total electricity production, as compared to solar, where only $3 \%$ (215 MW) were reported [4], [5]. The presence of the Black Sea represents another advantage for the Romanian energy systems, since additional sources of generation coming from this marine environment may be considered, in particular the wind and wave power [6-8]. Gradually, the renewable systems operating in the vicinity of coastal areas are becoming a reality, this being the case of some enclosed basins, such as the Mediterranean Sea [9], [10] or the areas facing the ocean [11-14].

\section{ROMANIAN ENERGY PROFILE}

A first perspective of the Romanian energy system will be provided by using the data included in the CIA - World Factbook [3], where several indices will be discussed, such as the electricity production, presented in Figure 1. Looking at these values, one may notice that Romania, with 62.16 billion $\mathrm{kWh}$, is on the 12th position, which is below the average value computed from the total data. It is important to mention that this average value is biased by the 
productions reported by France and Germany, which are almost twice than the values reported by Italy, Spain or United Kingdom, respectively. On the other end, one may found Luxembourg, which has a production capacity directly related to its population and country size.

Figure 2 illustrates the electricity profile of each country, from which one may notice that several countries are positioned as a net exporter. Romania is included in this category, which is dominated by France and Germany, including also countries like
Bulgaria, Czech Republic, Estonia, Ireland, Portugal, Slovenia or Sweden, respectively.

A more detailed assessment of the electricity budget is presented in Figure 3, where, beside the contributions coming from the fossil fuels and nuclear, where the renewable sources were also added. In the case of Romania, one may observe that the main source of power is related to the fossil fuels $(46.7 \%)$, while, on the opposite end, the lowest contribution comes from nuclear $(5.4 \%)$.

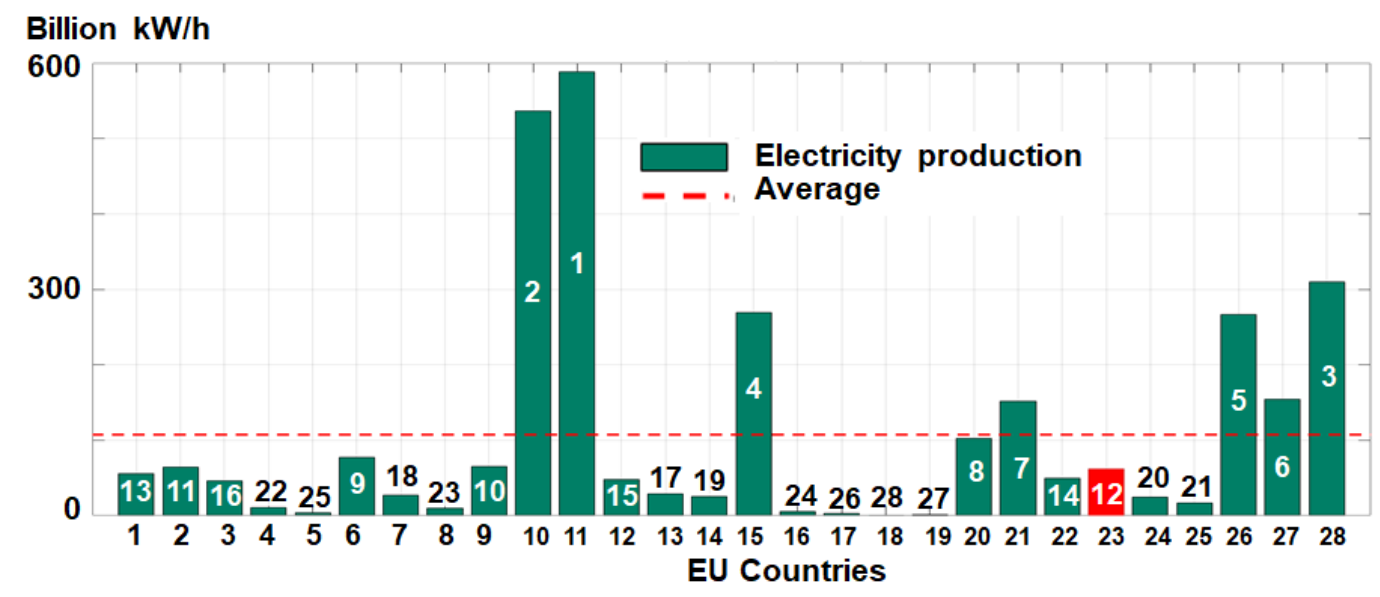

1. Austria; 2. Belgium; 3. Bulgaria; 4. Croatia; 5. Cyprus; 6. Czech Republic; 7. Denmark;

8. Estonia; 9. Finland; 10. France; 11. Germany; 12. Greece; 13. Hungary; 14. Ireland;

15. Italy; 16. Latvia; 17. Lithuania; 18. Luxembourg; 19. Malta; 20. Netherlands; 21. Poland;

22. Portugal; 23. Romania; 24. Slovakia; 25. Slovenia; 26. Spain; 27. Sweden; 28. United Kingdom

Fig. 1. Electricity production reported by each EU country for the year 2015. The numbers mentioned in the chart highlight the position occupied by each country from the EU group
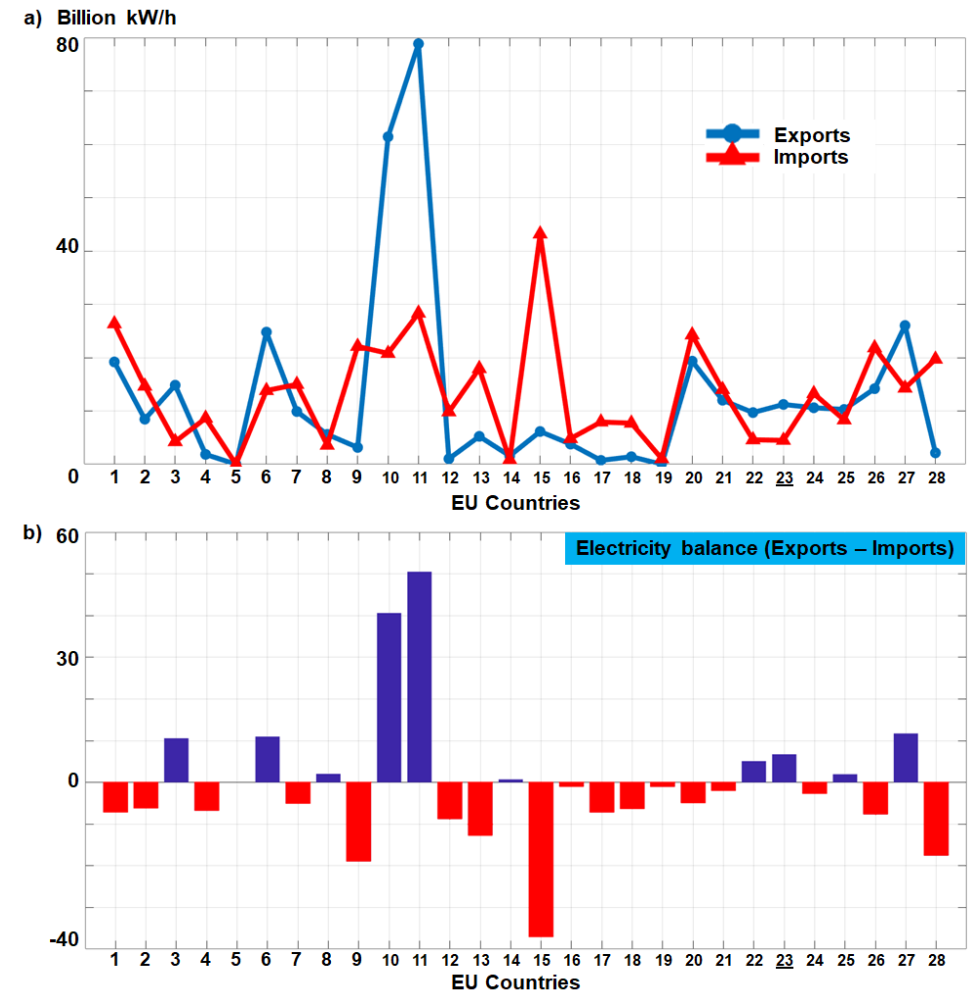

Fig. 2. The structure of the national electricity network reported for 2015 , where: a) imports and exports; b) electricity balance. 
(\%)

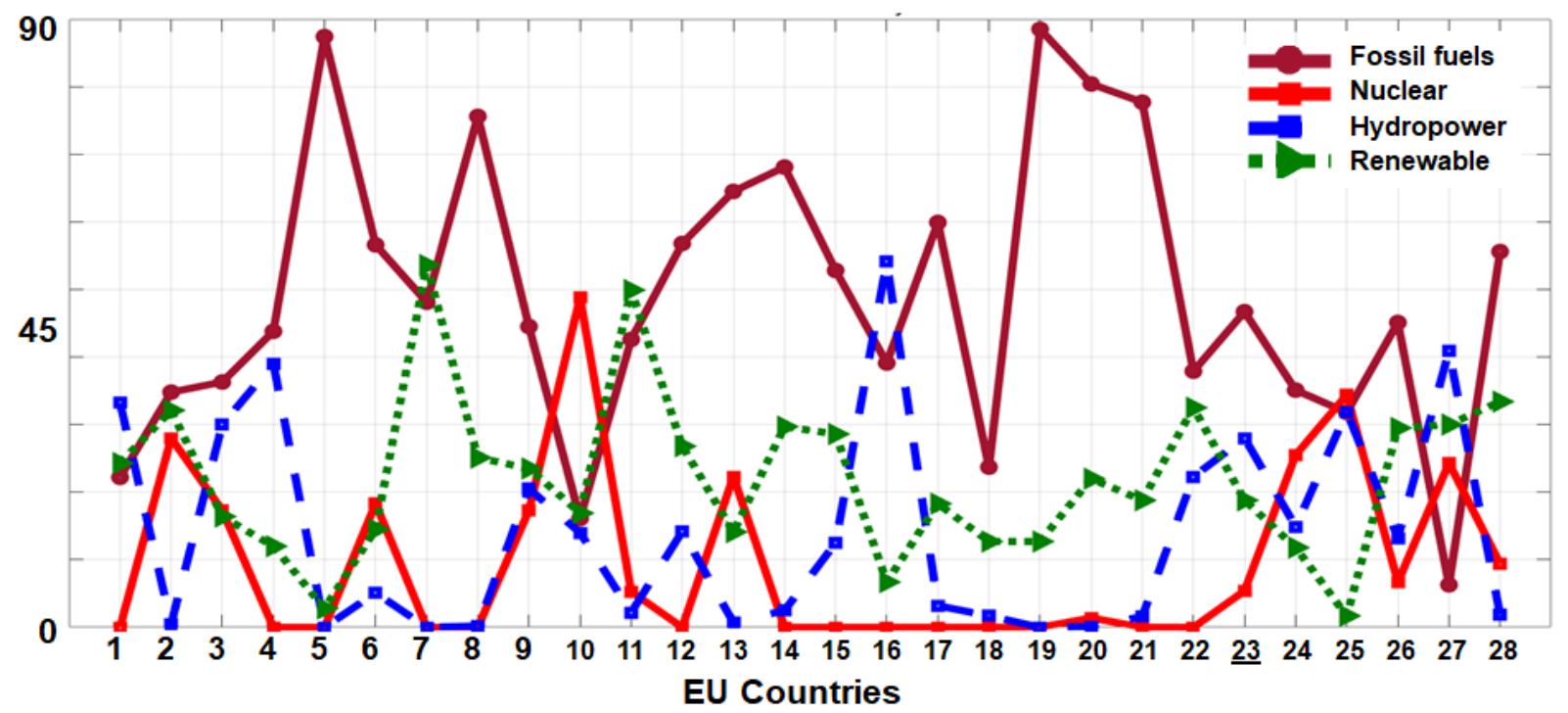

Fig. 3. The electricity mix reported by the EU countries (in 2015).

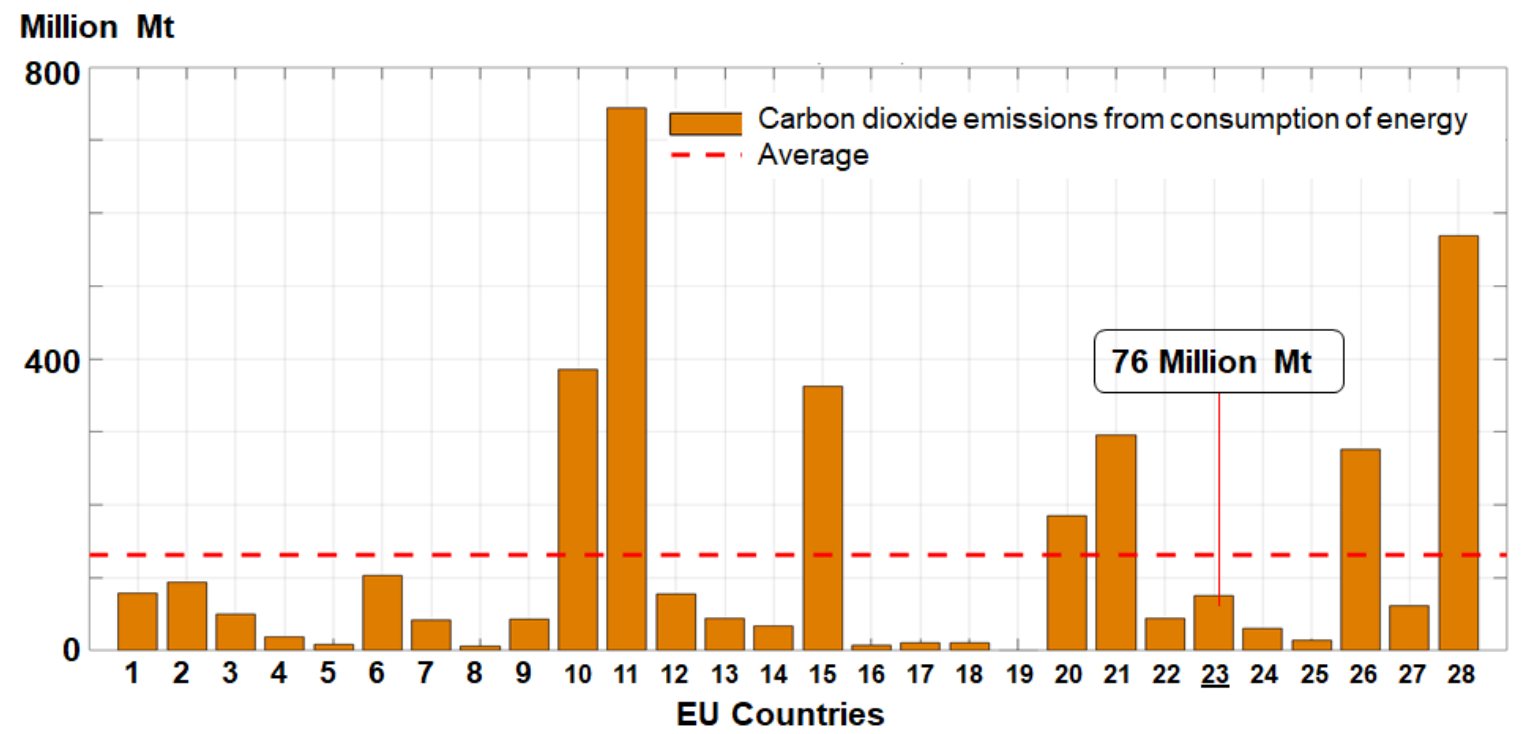

Fig. 4. The $\mathrm{CO}_{2}$ emissions associated with the EU countries (estimated for 2015).

As regarding the fossil fuel consumptions, the highest peaks are being reported by Cyprus, Estonia, Ireland and Malta, which, in some cases, may reach $90 \%$. For the hydropower sector, better values are being reported by Croatia, Latvia and Sweden, while, for Romania, the authors can mention a percentage of $28 \%$. Looking at some other renewable sources, the authors noticed that Denmark and Germany are defined by more consistent values, which exceed the share coming from fossil fuels resources.

The $\mathrm{CO}_{2}$ emissions represent one of the indicators which define the level of pollution. Figure 4 illustrates the distribution of these values, from which one can observe that Germany is on the first place, with 744 million Mt (Metric ton), being followed by the UK with 569 million Mt. As expected, most of the countries (21 of 28) report emissions, which are below the average value, this being also the case of Romania for, which a 76 million Mt can be a representative value for the year 2015.

As a next step, the evolution of the Romanian energy market is discussed by considering data coming from the Global Energy Statistical Yearbook [15], covering the time interval from 1990 to 2016. Figure 5 illustrates the evolution of the electricity production, from which the authors noticed that the Romanian market reveals significant variations during the interval 1990-2013. A maximum of 68 TWh is registered during the years 2015 and 2016, while a minimum of $51 \mathrm{TWh}$ is accounted for the year 1999. As for Europe and UE, it is visible the ascendant evolution reported between 1990 and 2008, being followed by a peak, which marks a slowly decay of the production for the next interval (2010-2016). 
(a) Electricity production (TWh)

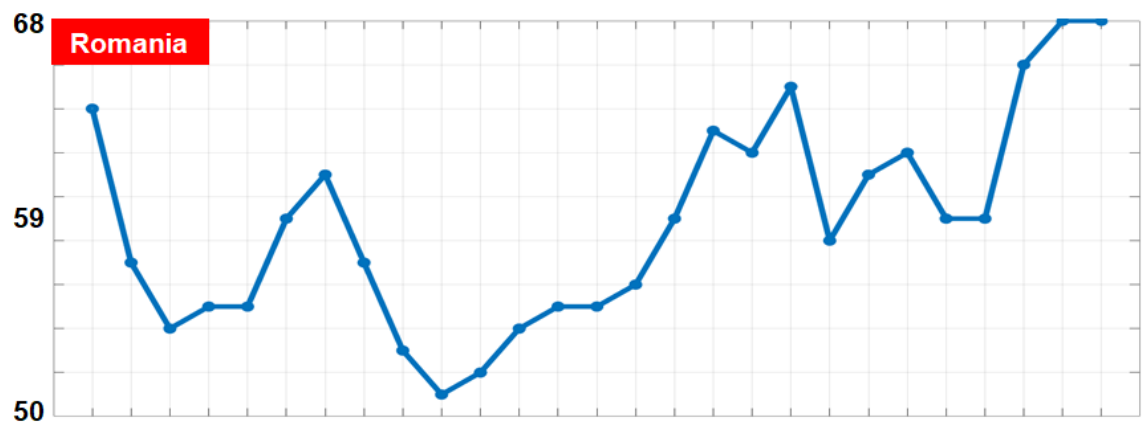

(b) 4000

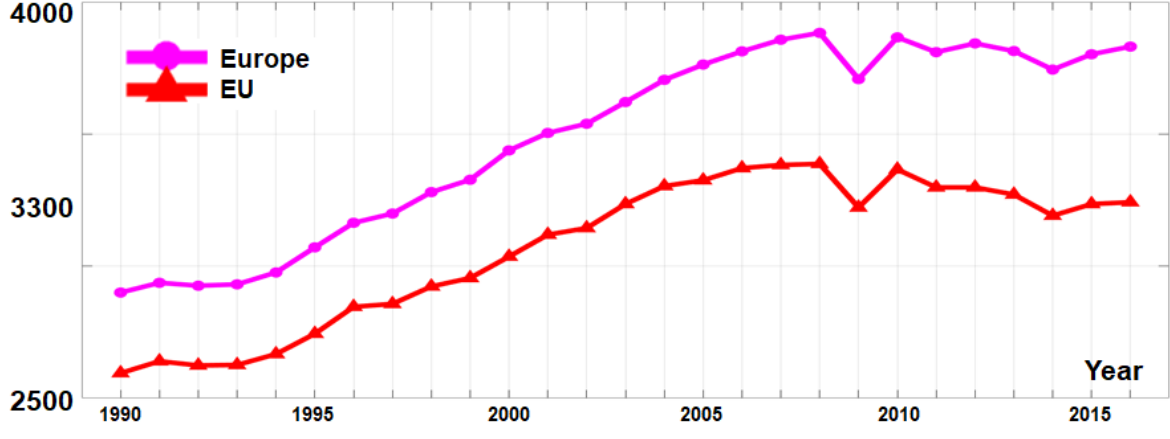

Fig. 5. Electricity production reported for the time interval from 1990 to 2016: a) Romania; b) Europe and UE

\section{Electricity balance of trade (TWh)}

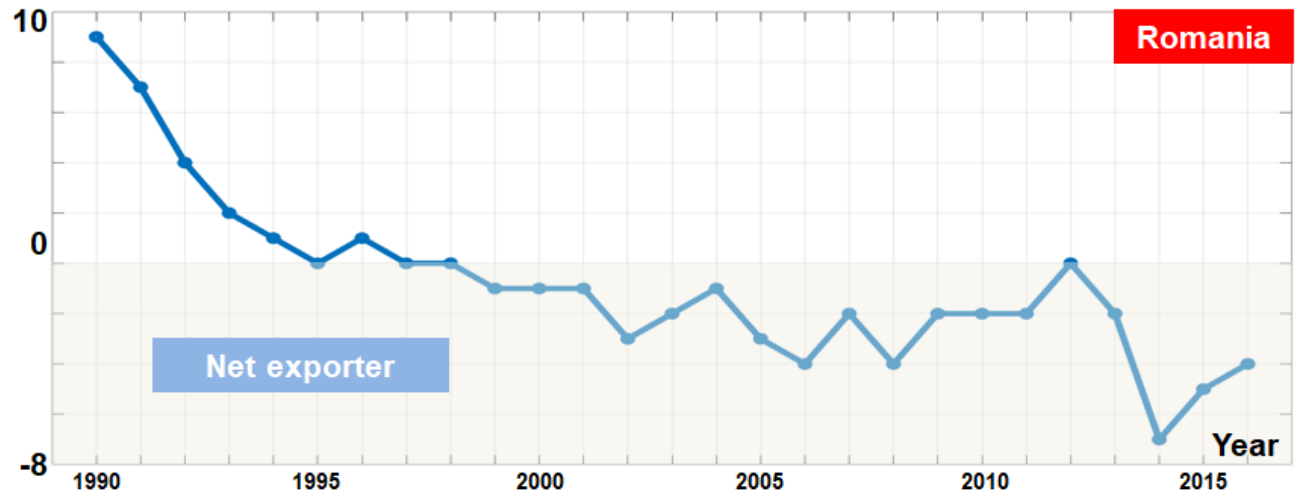

Fig. 6. Romanian electricity balance of trade

Share of renewables in electricity production (\%)

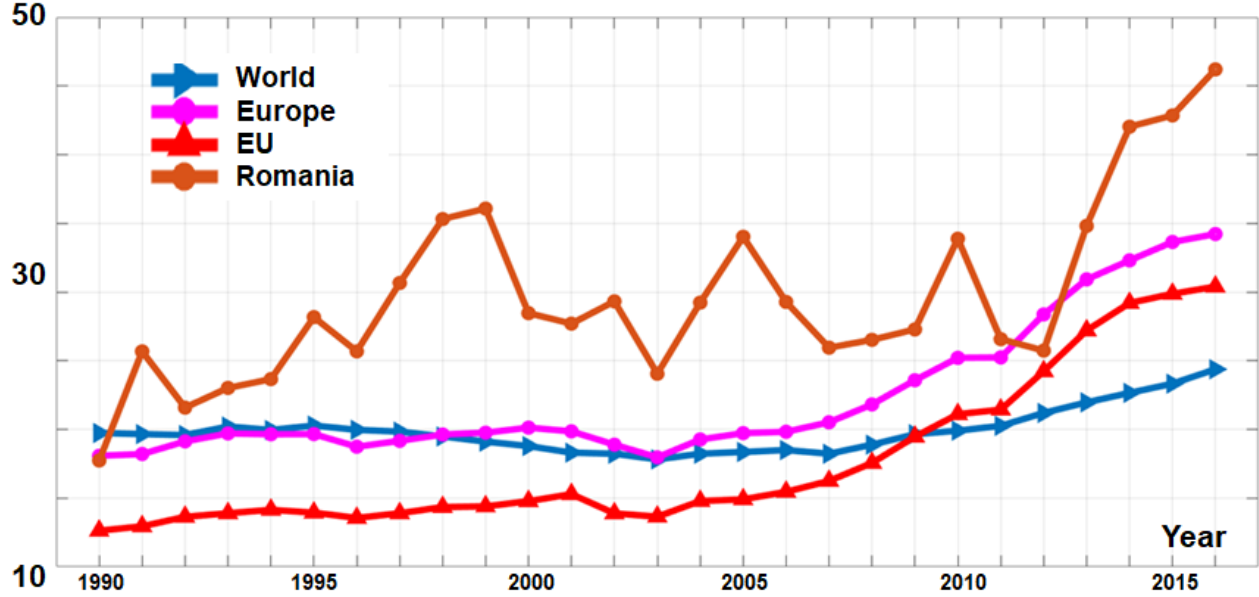

Fig. 7. Electricity share coming from renewables 


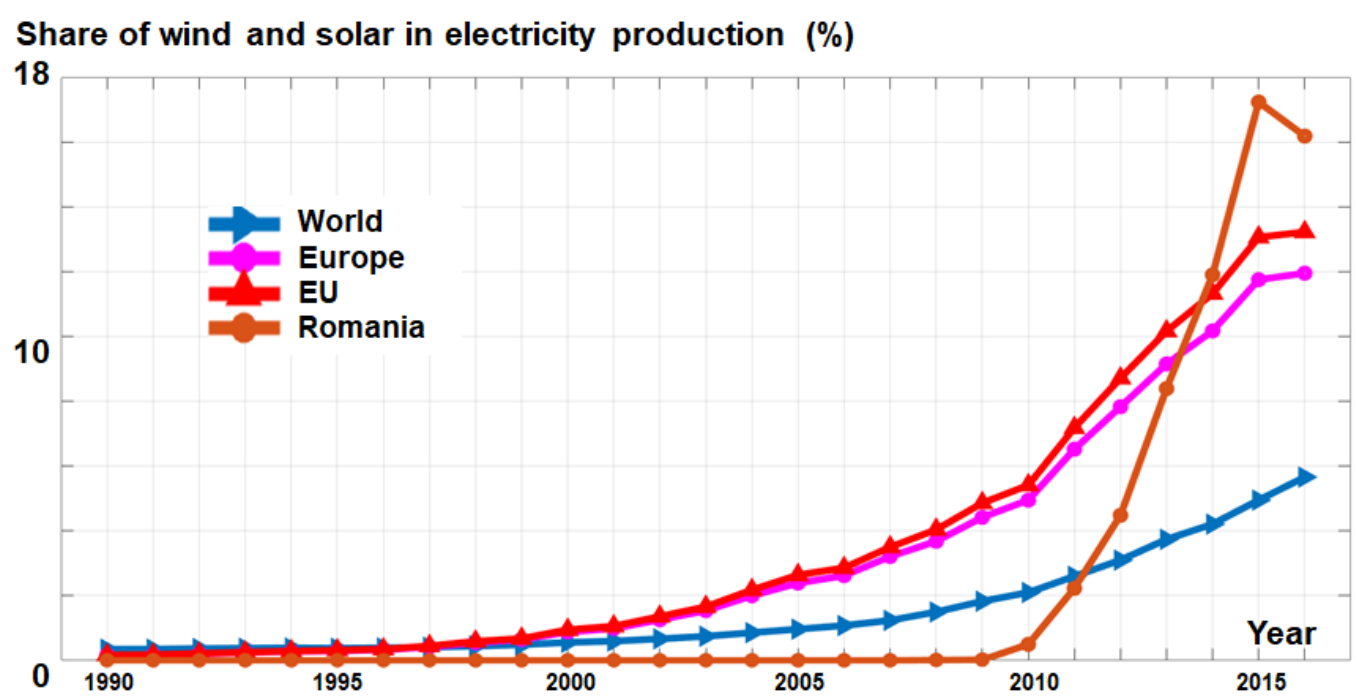

Fig. 8. Wind and solar contribution to the electricity production

Looking at the balance of trade (Fig. 6), the authors noticed that, since 1995, Romania has consolidated his position as a net electricity exporter, reaching a maximum peak of $7 \mathrm{TWh}$, for the year 2014. Although the energy production seems to be constant in the interval 2015-2016, looking at this chart, one may see that the exports are gradually reducing, reaching a value of $4 \mathrm{TWh}$, which is similar to the values reported for years 2016 and 2018, respectively.

In 2007 Romania joins the European Union, which sets an ambitious target of $20 \%$ share from renewable sources by the year 2020. From the infomation presented in Figure 7, one may notice that Romania has already achieved this milestone, reporting a $26 \%$ at that time, while for the year 2016 was indicated a percentage of $46.2 \%$ which easily exceed the milestone indicated by the UE for the year 2030.

Reported on a Global, European and UE level, we can see that Romania reveal much better values, being reported an upward trend for the interval 20122016. A significant percentage of these values are coming from wind and solar, as we can observe from Figure 8. On a European level these two sector, seems to gain momentum starting with the year 2000 reaching in 2016 a share of $14 \%$, compared to the Global values where only $5.7 \%$ is indicated.

For Romania, more noticeable progress are being related to the year $2010(0.5 \%)$, after which the market expanded very fast reaching a share of $12 \%$ in 2014, and a maximum of $17.2 \%$ in 2015, respectively. By looking at these values, we can definitely say that there is interest in the renewable sources, more promising results being reported on a European level, especially after the year 2010.

\section{CONCLUSIONS}

A general perspective of the Romanian energy market was presented in this paper, in order to establish the current progress reported by the renewable sector. According to the statistical data presented in this work, it seems that Romania presents better results in terms of the $\mathrm{CO}_{2}$ emissions (lower values), it is considered to be a net electricity exporter, revealing at the same time a consistent electricity share coming from renewable sources, which, at this moment, exceed the values reported on an European scale.

Besides these natural sources, since Romania is located in a favorable position in the Black Sea basin and it is possible that in the near future some additional resources to be considered for extraction, such as the wave and offshore wind power [16-18]. A previous study has already highlighted that the western part of the Black Sea is defined by more consistent marine resources, which make viable the idea to develop a wind and wave project. More than this, since during the winter time the Romanian shoreline is heavily affected by the storm events, it seems that the implementation of a wave farm will represent a suitable solution for the coastal protection [19]. Finally, the authors need to point out that, at this moment, there is interest in the Romanian renewable sector, with the mention that, definitely, there is room for an improvement, a possible direction being related to the use of natural sources provided by the Black Sea.

\section{ACKNOLEDGMENT}

This work was supported by a grant of Ministery of Research and Innovation, CNCS - UEFISCDI, project number PN-III-P1-1.1-PD-2016-0235, within PNCDI III.

\section{REFERENCES}

[1] *** Energy Production \& Changing Energy Sources, Our World in Data, https://ourworldindata.org/energy-production-andchanging-energy-sources (accessed: 14-Jun-2018). 
[2] *** P. O. of the E. Union, EU energy in figures: statistical pocketbook 2017, (Accessed: 30 Nov 2017), https://publications.europa.eu/en/publicationdetail/-/publication/2e046bd0-b542-11e7-837e-

01aa75ed71a1/language-en/format-PDF (Accessed: 14-June-2018).

[3] *** The World Factbook - Central

Intelligence Agency,

https://www.cia.gov/library/publications/the-world-

factbook/geos/ro.html (Accessed: 14 June 2018).

[4] Diaconu O., G. Oprescu, and R. Pittman, Electricity reform in Romania, Utilities Policy, vol. 17, no. 1, pp. 114-124, Mar. 2009.

[5] G. Dragomir, Șerban A., Năstase G., Brezeanu A. I., Wind energy in Romania: A review from 2009 to 2016, Renewable and Sustainable Energy Reviews, vol. 64, pp. 129-143, 2016.

[6] Raileanu A., Onea F., Rusu E., Assessment of the wind energy potential in the coastal environment of two enclosed seas. New York, IEEE, 2015.

[7] Onea F., Rusu E., Efficiency assessments for some state of the art wind turbines in the coastal environments of the Black and the Caspian seas, Energy Explor. Exploit., vol. 34, no. 2, pp. 217-234, 2016.

[8] Zanopol A. T., Onea F., Rusu E., Studies concerning the influence of the wave farms on the nearshore processes, International Journal of Geosciences, vol. 5, p. 728, 2014.

[9] Onea F., Deleanu L., Rusu L., Georgescu C., Evaluation of the wind energy potential along the Mediterranean Sea coasts, Energy Explor. Exploit., vol. 34, no. 5, pp. 766-792, 2016.

[10] Onea F., Rusu L., Coastal impact of a hybrid marine farm operating close to the Sardinia Island. New York, IEEE, 2015.
[11] Rusu E., Onea F., Study on the influence of the distance to shore for a wave energy farm operating in the central part of the Portuguese nearshore, Energy Conv. Manag., vol. 114, pp. 209-223, 2016.

[12] Bento A. R., Rusu E., Martinho P., Guedes Soares C., Assessment of the changes induced by a wave energy farm in the nearshore wave conditions, Computers \& Geosciences, vol. 71, pp. 50-61, 2014. [13] Rusu E., Guedes Soares C., Wave Energy Assessments in the Coastal Environment of Portugal Continental, pp. 761-772, 2008.

[14] Rusu L., Onea F., The performance of some state-of-the-art wave energy converters in locations with the worldwide highest wave power, Renew. Sust. Energ. Rev., vol. 75, pp. 1348-1362, 2017.

[15] World Energy Statistics Enerdata, https://yearbook.enerdata.net/. (accessed: 30-June2018).

[16] Onea F., Rusu E., Wind energy assessments along the Black Sea basin, Meteorol. Appl., vol. 21, no. 2, pp. 316-329, 2014.

[17] Rusu E., Onea F., Hybrid Solutions for Energy Extraction in Coastal Environment, in 2017 2nd International Conference on Advances on Clean Energy Research (icacer 2017), vol. 118, Cui W. and Rusu E., Eds. Amsterdam: Elsevier Science Bv, pp. 46-53, 2017.

[18] Ganea D., Amortila V., Mereuta E., Rusu E., A joint evaluation of the wind and wave energy resources close to the Greek Islands, Sustainability, vol. 9, no. 6, p. 1025, 2017.

[19] Zanopol A. T., Onea F., Rusu E., Coastal impact assessment of a generic wave farm operating in the Romanian nearshore, Energy, vol. 72, pp. 652 670,2014 